\title{
RESPONSABILIDADE FISCAL E SISTEMA DE FINANÇAS PÚBLICAS DE CRISE
}

\author{
FISCAL RESPONSIBILITY AND PUBLIC FINANCE'S CRISIS SYSTEM
}

\begin{abstract}
iD Paulo Roberto dos Santos Corval Universidade Federal Fluminense Doutor em Ciência Política Professor de Direito Financeiro e Tributário Professor do Programa de Pós-Graduação em Direito Constitucional da UFF (PPGDC/UFF) Niterói / Rio de Janeiro / Brasil paulocorval@id.uff.br

Gabriel Garcia Rodrigues de Barros Universidade Federal Fluminense Mestrando em Direito Constitucional Professor do Programa de Pós-Graduação em Direito Constitucional da UFF (PPGDC/UFF) Advogado

Niterói / Rio de Janeiro / Brasil gabrielgarciarb@gmail.com
\end{abstract}

Resumo: A Lei de Responsabilidade Fiscal impõe rígidos mecanismos de controle aos administradores públicos. Para suavizar essas imposições em tempos extraordinários, porém, o legislador previu regras excepcionais para as situações de calamidade pública. Dedica-se o artigo, por esse motivo, à delimitação do que se entende por calamidade pública e ao discurso que a comunidade jurídica brasileira vem atribuindo ao sistema de calamidade financeira que começou a se desenhar. Embora os dispositivos legais, a jurisprudência e a literatura indiquem uma interpretação mais restritiva, a aplicação prática do sistema e a edição da Lei Complementar $n^{\circ}$ 173/2020, apoiada em conjugadas transformações da ordem constitucional, moveram-se em sentido contrário, ampliativo, erigindo novel sistemática de exceção para o controle de crises na disciplina jurídica das finanças públicas no país.

Palavras-chave: finanças públicas; responsabilidade fiscal; calamidade financeira.

Abstract: The Fiscal Responsibility Law imposes strict control mechanisms on public administrators. To soften these impositions in extraordinary times, however, the legislator foresaw exceptional rules for situations of public calamity. For this reason, the article is dedicated to the delimitation of what is meant by public calamity and to the discourse that the Brazilian legal community has attributed to the financial calamity system that began to be designed. Although the legal provisions, the jurisprudence of the Supreme Federal Court and the legal literature indicate a more restrictive interpretation, the practical application of the system and the edition of Complementary Law No. 173/2020, supported by conjugated transformations of the constitutional order, they moved in the opposite direction, enlarging, creating a systematic novel of exception for the control of crises in the discipline of public finances in the country.

Key-words: public finances; fiscal responsibility; financial calamity. 
Para citar este artigo (ABNT NBR 6023:2018)

CORVAL, Paulo Roberto dos Santos; BARROS, Gabriel Garcia Rodrigues de. Responsabilidade fiscal e sistema de finanças públicas de crise. Revista Thesis Juris - RTJ, São Paulo, v. 10, n. 2, p. 375-401, jul./dez. 2021. http://doi.org/10.5585/rtj.v10i2.18938.

\section{Introdução}

O artigo, alicerçado no marco da Análise Integral do Direito (CORVAL, 2017), analisa o quadro regulatório dos artigos 65 e 66 da Lei de Responsabilidade Fiscal (LRF). Parte-se da hipótese de que a aplicação do sistema de calamidade financeira da LRF, que se deu em razão da crise fiscal verificada em vários dos Estados brasileiros a partir do ano de 2015, sofreu mutações em relação ao que se dispunha no momento de sua edição, erigindo, ainda em fase inicial, novel sistemática de exceção para o controle de crises na disciplina jurídica das finanças públicas no país.

O controle de crises econômicas pela via normativa aponta para o que se tem chamado de "jurisprudência de crise". Trata-se, em poucas palavras, de uma intervenção do Poder Judiciário na política macroeconômica, por meio de decisões em que verifica a constitucionalidade de medidas de austeridade fiscal (MAGALHÃES, 2017, p. 12). Ao assumirem esse papel, os tribunais oscilam entre a interpretação normativa da Constituição e a adaptação da norma às circunstâncias econômicas (DIAS e TEDESCO, 2020). Como um dos casos mais emblemáticos desse fenômeno, tem-se a resposta do Tribunal Constitucional português à crise de 2007/2008 (PINHEIRO, 2014).

É possível identificar, na jurisprudência recente do Supremo Tribunal Federal, sinais de intervenção na política econômica similares à ideia de jurisprudência de crise. Nesse artigo, serão analisadas algumas das decisões que aferiram a constitucionalidade da declaração de calamidade financeira por alguns Estados brasileiros.

Examinaram-se também os debates parlamentares que envolveram a edição da Lei de Responsabilidade Fiscal $^{1}$ e a já referida jurisprudência do Supremo Tribunal Federal $^{2}$, bem como a bibliografia especializada. Também foram verificadas as legislações de calamidade

\footnotetext{
${ }^{1}$ Os debates se encontram à disposição para consulta no endereço eletrônico https://www2.camara.leg.br/atividade-legislativa/legislacao.

${ }^{2}$ Os julgados foram levantados por meio da consulta levada a efeito no endereço eletrônico do STF, buscando-se os acórdãos e decisões monocráticas que contivessem o termo "Lei de Responsabilidade Fiscal", ou o termo "Lei Complementar 101/2000", e o termo "art. 65", ou o termo "art. 66", e suas variantes. Dos resultados, foram filtrados os julgados que de fato contribuíam para esta pesquisa.
} 
financeira nos Estados brasileiros ${ }^{3}$ e, quanto à Lei Complementar $n^{\circ} 173 / 2020$, pesquisaram-se os debates parlamentares no Congresso ${ }^{4}$ e a incipiente bibliografia sobre o assunto.

Na próxima seção, de número 2, voltar-se-á à redação originária dos dispositivos da LRF, acompanhados de uma análise conceitual, jurisprudencial e teórica sobre seu sentido ao tempo de sua construção legislativa e vigência, inclusive com a indicação, no período, da abordagem do assunto na jurisprudência do Supremo Tribunal Federal.

Na seção 3 o foco é a prática do sistema de calamidade financeira. A intenção é demonstrar como esses dispositivos foram aplicados pelos Estados brasileiros, quando passavam por crises econômicas, até o início do ano de 2020 (antes da pandemia da COVID19).

O estudo da Lei Complementar $n^{\circ} 173 / 2020$, que alterou a disciplina do sistema de calamidade financeira na LRF, ocupa a seção 4 . O objetivo será compreender de que maneira esse novo marco normativo mantém ou rompe com a dinâmica em vigor até então. Na sequência, as considerações finais.

\section{Primeiro momento: a análise conceitual da LRF}

Localizados nas Disposições Finais e Transitórias da LRF, os artigos 65 e 66, antes das modificações introduzidas pela Lei Complementar $n^{\circ} 173 / 2020$, previam medidas de abrandamento de algumas regras fiscais fixadas pela LRF em três circunstâncias de caráter excepcional: a calamidade pública, o estado de defesa e o estado de sítio.

O estado de defesa e o estado de sítio são institutos do direito constitucional de manejo excepcional (CRFB, artigos 136 a 139). Jamais foram utilizados sob a Constituição de 1988 e são de competência exclusiva do governo federal, envolvendo o presidente da República, os Conselhos da República e da Defesa Nacional e o Congresso Nacional.

$\mathrm{O}$ estado de defesa tem como pressupostos materiais as instabilidades institucionais (com causas não explicitadas) e/ou as calamidades naturais, como dita o artigo 136 da CRFB/88. Conforme José Afonso da Silva, nesta segunda hipótese, embora a instabilidade faça parte da essência da calamidade, ela deverá ser de grandes proporções para ensejar a decretação

\footnotetext{
${ }^{3}$ Quanto aos Estados, foi realizada consulta aos portais de pesquisa online, por meio dos seguintes termos-chave: "[nome do Estado] + calamidade financeira" (exemplo: "Amapá calamidade financeira"); e "[nome do Estado] + decreta calamidade" (exemplo: "Amapá decreta calamidade"). Nesse processo, houve restrição da data dos resultados, para que só aparecessem na consulta as informações publicadas no período entre 01/01/2000 e $29 / 02 / 2020$.

${ }^{4}$ Disponível em https://www2.camara.leg.br/atividade-legislativa/legislacao.
} 
do estado de defesa, de modo que não se cogitará do referido instituto quando não houver grave perturbação à ordem pública ou à paz social (SILVA, 2005, p. 764).

O estado de sítio, passível de maior extensão temporal, tem como base de sua decretação a frustração, anterior, das medidas tomadas durante o estado de defesa ou, ainda, situação de comoção nacional, guerra ou resposta à agressão armada. Guilherme Peña de Moraes acentua que haverá controle político preventivo, concomitante e sucessivo, sem prejuízo do controle jurisdicional das lesões a direitos fundamentais verificadas durante a decretação (MORAES, 2020, p. 644-645).

Numa e noutra situação, defesa ou sítio, inexiste qualquer previsão constitucional de medida excepcional na área das finanças públicas, concentrando-se os dispositivos a eles atinentes nas restrições aos direitos civis e políticos e à propriedade.

Não obstante a incidência do artigo 65 no estado de defesa e de sítio, o cerne do dispositivo é a hipótese de calamidade pública. A LRF, reconhecendo-a, não fixou suas causas. Deixou, assim, à apreciação legislativa, caso a caso, o seu reconhecimento e delimitação. A calamidade pública, nessa direção, seria aquela considerada como tal pelo Legislativo (Congresso Nacional, no caso da União, e Assembleias Legislativas, na hipótese dos Estados e dos Municípios). Sua duração, amarrada estruturalmente à sua materialidade, é aquela que o próprio Legislativo estabelecer.

A ampla margem de subjetividade conferida pela LRF, sem embargo, encontra limites nos usos que o texto constitucional fixou para a ideia de calamidade, tendo em vista, inclusive, que se prevê, na Constituição, uma regulação de situação de emergência que, ao menos quanto ao estado de defesa, refere a ideia de calamidade.

Na Constituição de 1988, a expressão “calamidade pública” aparece cinco vezes. O sentido predominante parece ser o de fato natural imprevisível e urgente, que cause grave instabilidade social. Pode ser que o constituinte tenha querido trazer para a Carta Magna a ideia que no Direito Civil é associada ao caso fortuito ou à força maior ${ }^{5}$, com duas diferenças: (i) no sistema constitucional parece ser irrelevante a distinção privatista entre fato imprevisível ou previsível, desde que haja o resultado instabilidade; e (ii) no sistema constitucional é necessário que a instabilidade seja grave o suficiente para ensejar o estado de excepcionalidade, ou seja, em sentido distinto da premissa do direito privado, a calamidade precisa ser pública.

\footnotetext{
${ }^{5}$ Flávio Tartuce conceitua o caso fortuito como o evento totalmente imprevisível e a força maior como o evento previsível, mas inevitável (TARTUCE, 2017, p. 472).
} 


\section{CORVAL, Paulo Roberto dos Santos; BARROS, Gabriel Garcia Rodrigues de. Responsabilidade fiscal e sistema de finanças públicas de crise}

Outra consideração: tanto no artigo 148 , I, quanto no artigo $167, \S 3^{\circ}$, ambos da CRFB/88, a expressão calamidade pública é acompanhada do sintagma guerra ${ }^{6}$. Ao nivelar a calamidade à situação de guerra declarada, o constituinte parece querer equiparar o sentido do que vem a ser calamidade com a instabilidade gerada pelo conflito armado, interpretação que excluiria, em nossa visão, o alcance dos abalos cíclicos do sistema econômico, uma vez que não se configuraria, aí, situação tão grave quanto as de conflito bélico.

Ao se manifestar sobre o tema no passado, o Supremo Tribunal Federal já empregou raciocínio similar. Em seu voto na ocasião do julgamento da Medida Cautelar em Ação Direta de Inconstitucionalidade $n^{\circ}$ 4.048-1/DF, julgada em 14/05/2008, o Ministro Gilmar Mendes salientou que os conceitos de "guerra", "comoção interna" e "calamidade pública" representam, sem dúvida, situações fáticas de extrema gravidade e de consequências imprevisíveis para a ordem pública e a paz social, de forma que requerem medidas singulares e extraordinárias (BRASIL, 2008). Ou seja, para o ministro, a imprevisibilidade e a extrema gravidade são atributos inafastáveis a esses conceitos.

O raciocínio que se extrai do trecho acima é o de que a crise é uma consequência da calamidade, da guerra ou da comoção, e não causa. Ou seja, o abalo do sistema econômico causado por fatores que não sejam os de "extrema gravidade e de consequências imprevisíveis", nas palavras do ministro, não teria o condão de se enquadrar na amplitude semântica do termo "calamidade" para os fins de abertura de crédito extraordinário ou instituição de empréstimo compulsório.

Anos depois, em 2019, o Supremo Tribunal Federal foi instado a se manifestar mais concretamente sobre o assunto. Na Ação Cível Originária n ${ }^{\circ} 3.271$, o Estado de Mato Grosso pedia, em tutela de urgência, que a União fosse condenada a deixar de aplicar uma das sanções previstas na LRF decorrentes da violação à determinação de redução de despesas com pessoal aos limites fixados pela lei. Um dos argumentos usados pela Procuradoria do Estado do Mato Grosso foi o de que a Assembleia Legislativa estadual havia reconhecido o estado de calamidade pública, nos termos do artigo 65 da LRF, de modo que a sanção discutida estaria suspensa.

Em decisão liminar, a relatora Ministra Rosa Weber modulou a força do estado de calamidade pública reconhecido pelo Parlamento mato-grossense, sustentando que o processo desvirtuara a razão de ser do sistema excepcional previsto na LRF. Nas palavras da ministra, a definição de calamidade pública está associada a fatos extraordinários do mundo físico ou de

${ }^{6}$ No artigo 167, além da guerra, prevê-se também outro conceito indeterminado, a comoção interna. 
força maior, de causa não imputável à Administração. A seu aviso, seria paradoxal que a violação aos prazos legais da LRF fosse invocada como causa da calamidade para justificar a si própria (BRASIL, 2019b).

A interpretação da ministra corrobora o raciocínio anteriormente explicitado, decorrente da decisão aqui referenciada do ministro Gilmar Mendes. A conclusão proveniente da interpretação do ministro, reitere-se, fora no sentido de que, para os padrões da LRF, a crise econômica só deve ser admitida como consequência da calamidade, e não como causa, sob pena de, nas palavras de Rosa Weber, se tornar o "gatilho justificador da constatação do estado de calamidade" (IBID.).

Conforme noticiou a imprensa em 2016, o Ministério da Fazenda também não reconhecia, à época, crises econômicas como hipótese suficiente a caracterizar a calamidade pública a que se refere a LRF (G1, 2016).

Parte da literatura jurídica sobre o tema ia ao encontro desta interpretação. Em artigo datado de julho de 2016, Marcus Abraham já sinalizava que "muitos argumentam que o conceito abarcaria exclusivamente fatos naturais" (ABRAHAM, 2016). Abraham faz referência, assim, à controvérsia que aqui se analisa, apontando que a interpretação que restringe o conceito de calamidade pública aos termos anteriormente delineados tem ganhado apelo entre os juristas.

Nesse sentido também caminhavam as reflexões do professor José Maurício Conti, que, em artigo publicado no Portal Consultor Jurídico em 2016, considerava "exótica" a decretação de calamidade pública em razão de problemas financeiros graves, caracterizando esse tipo de medida como um extrato da "administração-bombeiro" (CONTI, 2016). O autor ainda questionava se a má gestão financeira poderia ser considerada um fato imprevisível, ou se, por outro lado, seria uma tragédia decorrente de um conjunto de atos deliberados (IBID.).

Essa reflexão ganha profundidade quando se foca o estudo na LRF. A redação dos dispositivos que regulamentam o estado de calamidade pública para fins fiscais oferta pistas capazes de indicar o caminho imaginado pelos legisladores.

Para as situações de calamidade, estado de defesa ou sítio, a LRF prevê o afastamento dos prazos e dos efeitos jurídicos das regras fiscais dos artigos 23, 31 e 70. Além disso, dispensa o ente em situação de crise do "atingimento dos resultados fiscais" normalmente fixados na Lei de Diretrizes Orçamentárias e, também, das restrições à limitação de empenho de que trata o artigo $9^{\circ}$ do diploma.

Prevê a LRF, ademais, no artigo 66, que, na hipótese de se apurar "crescimento real baixo ou negativo do Produto Interno Bruto (PIB) nacional, regional ou estadual por período 
igual ou superior a quatro trimestres", os prazos para o cumprimento das exigências dos artigos 23, 31 e 70 serão duplicados.

A compreensão do impacto da LRF na ordem jurídica brasileira e do sistema excepcional de regulação das finanças públicas remonta à sua gestação. O projeto inicial de lei complementar (PLP n ${ }^{\circ}$ 18/1999) fora enviado pelo Poder Executivo à Câmara dos Deputados como medida integrante do que se chamou à época Programa de Estabilidade Fiscal - PEF. Foram protagonistas nesse processo os Ministérios do Orçamento e Gestão, da Fazenda e da Previdência e Assistência Social (nomenclaturas da época), como registrado na mensagem encaminhada pelos então ministros dessas pastas à Presidência da República apresentando a proposta (BRASIL, 1999).

No projeto de lei original (PLP n 18/1999) previa-se, no Capítulo IV ("Das normas coercitivas para a correção dos desvios fiscais"), uma seção inteira dedicada às situações excepcionais e de baixo crescimento do PIB. Tratava-se da Seção VIII ("Das situações excepcionais ou de baixo crescimento econômico"). Além disso, o projeto excetuava do conceito de transferência voluntária adotado pela lei os recursos transferidos por um ente da Federação a outro durante calamidade pública ${ }^{7}$.

Substitutivo ao projeto de lei trouxe várias alterações ao texto original do projeto de lei. Alocou as previsões sobre calamidade e baixo crescimento econômico num capítulo final, o Capítulo IX ("Das disposições finais e transitórias") ${ }^{8}$.

Em nova proposta, formulada posteriormente, propôs-se a inserção de um quarto parágrafo no artigo 67, a teor do qual "Na hipótese de se verificarem mudanças drásticas na condução das políticas monetária e cambial, o prazo referido no caput do art. 31 poderá ser ampliado em até quatro quadrimestres".

Em todo caso, é interessante observar que ambos os projetos separaram as disposições diferentes à calamidade pública daquelas atinentes ao baixo crescimento, apontando para a conclusão de que o conceito de "calamidade pública", no diploma, não abrangeria crises econômicas, melhor acomodadas pela outra categoria (baixo crescimento do PIB).

\footnotetext{
${ }^{7}$ Art. 87. Entende-se por transferência voluntária a entrega de todo e qualquer recurso por um ente da Federação em favor de outro, independente de seu título, e ainda que sob a forma de auxílios financeiros e contribuições, exceto: [...] VI - os recursos destinados a atender, exclusivamente, as despesas decorrentes de estado de calamidade pública, legalmente reconhecido.

${ }^{8}$ Art. 66. Na ocorrência de calamidade pública reconhecida pelo Congresso Nacional, no caso da União, ou pelas Assembléias Legislativas, na hipótese dos Estados e Municípios: I - será suspensa, enquanto perdurar a situação, a contagem dos prazos estabelecidos nos arts. 23,31 e 72; II - fica dispensada, no exercício, o atingimento dos resultados fiscais, nem promovida a limitação de empenho prevista no art. $9^{\circ}$. Parágrafo único. Aplica-se o disposto no caput no caso de estado de defesa ou de sítio, decretado na forma da Constituição.
} 
O projeto original da LRF, aliás, fazia essa distinção no próprio título da Seção VIII ("Das situações excepcionais ou de baixo crescimento econômico"), deixando ainda mais clara a compreensão histórica do legislador no sentido de diferenciar as duas situações.

Há, aí, mais um indício de que o sistema de calamidade financeira desenhado pela Lei de Responsabilidade Fiscal tem em seu escopo a finalidade de estruturar respostas legais a duas hipóteses bem delineadas: a calamidade pública e o baixo crescimento econômico, de modo que há também regramentos distintos para cada uma delas, não se confundindo uma com a outra.

\section{Segundo momento: a invocação do sistema de calamidade previsto na LRF pelos estados brasileiros}

Como visto, a despeito da margem de apreciação conferida ao Legislativo nos casos de uso do sistema com base na calamidade pública (e também nas outras hipóteses) a Constituição não deixa o termo "calamidade" sem delimitações. O instituto, excepcional, configura mecanismo jurídico eminentemente extraordinário, direcionado a situações de abalo institucional e social comparáveis à guerra, à comoção interna, ao estado de defesa e ao estado de sítio.

Isso não obstante, fato é que, na prática, a aplicação do sistema excepcional de calamidade financeira da LRF avançou com base em premissas que transcendem e alargam o entendimento estilizado e estabilizado. Nos últimos seis anos, aproximadamente, capitaneados pelo Estado do Rio de Janeiro, vários outros Estados brasileiros reconheceram o estado de calamidade pública com a finalidade específica de suspender as limitações arroladas nos artigos 65 e 66 da LRF.

Analisadas as situações de calamidade decretadas até o início da pandemia da COVID19, em março de 2020, observa-se já existir movimentação institucional em direção à estruturação de um sistema de calamidade financeira.

Foram encontradas na pesquisa que lastreou este artigo, ao todo, sete ocasiões em que os Estados brasileiros se valeram do sistema de calamidade financeira da LRF como válvula de escape às obrigações por ela impostas. Foram três ocorrências em 2016, uma em 2018 e três em 2019 (as decretações de 2020 foram supervenientes ao reconhecimento da pandemia da COVID-19, não sendo consideradas neste trabalho).

Em face do colapso fiscal que o assolava, o governo do Estado do Rio de Janeiro decretou, em 17/06/2016, estado de calamidade pública, por meio do Decreto nº 45.692/2016, 
antevendo, conforme o artigo $1^{\circ}$, o "descumprimento das obrigações assumidas em decorrência da realização dos Jogos Olímpicos e Paralímpicos de 2016”.

As razões que the deram ensejo estão expressas nas considerações iniciais que acompanham o decreto. Os motivos apontados são vários, mas o sentido geral está sintetizado no primeiro deles: "a grave crise econômica que assola o Estado do Rio de Janeiro". Uma das causas dessa crise econômica está apontada na consideração seguinte: "a queda na arrecadação, principalmente a observada no ICMS e nos royalties e participações especiais do petróleo".

O reconhecimento da calamidade foi corroborado pelo Legislativo, como determina o artigo 65 da LRF, por meio da Lei Estadual n ${ }^{\circ} 7.483 / 2016$. E o prazo inicialmente previsto de vigência da calamidade, final do ano de 2016, acabou prorrogado sucessivas vezes: até 31 de dezembro de 2018, pela Lei Estadual no 7.627/2017; até 31 de dezembro de 2019, pela Lei Estadual $n^{\circ} 8.272 / 2018$; e, finalmente, até 31 de dezembro de 2020, pela Lei Estadual $n^{\circ}$ $8.647 / 2019$.

O movimento feito pelo governo estadual fluminense, ao que tudo indica, caminhou em direção contrária àquela atribuída pelo Supremo Tribunal Federal ao sistema de calamidade financeira da LRF. Dissociou-se, além disso, da já exposta compreensão histórica do processo de promulgação da LRF quanto à redação dos seus artigos 65 e 66.

Seguindo o caminho inaugurado pelo Estado do Rio de Janeiro, o Estado do Rio Grande do Sul também se valeu das previsões dos artigos 65 e 66 da LRF como ferramenta de modulação dos efeitos da crise econômica que vinha enfrentando. Em 21/11/2016, o governo estadual decretou "calamidade financeira" por meio do Decreto n ${ }^{0} 53.303 / 2016$.

As motivações expressas no instrumento normativo são claras: os abalos econômicos são a razão de ser da calamidade. Entre as considerações iniciais do decreto cita-se a queda do PIB e da arrecadação tributária, bem como o aumento dos gastos públicos como causas da situação emergencial. As razões apresentadas podem ser sintetizadas na primeira delas: "a crise da economia brasileira está atingindo fortemente a capacidade de financiamento do setor público".

Não foram encontradas informações sobre a aprovação do reconhecimento da calamidade pela Assembleia Legislativa do Rio Grande do Sul. Tampouco, na pesquisa que lastreou o artigo, logrou-se encontrar matéria jornalística que fizesse menção a esse procedimento, como houve no caso do Rio de Janeiro e de outros Estados. Além disso, no site do Parlamento estadual, no campo destinado à pesquisa sobre legislação, quando inserido o termo "calamidade financeira", a única resposta enviada pelo portal é o já mencionado decreto editado pelo poder Executivo (RIO GRANDE DO SUL, 2020). 
A despeito da possível violação à obrigatoriedade da apreciação pela Assembleia Legislativa, o caso gaúcho traz uma interessante característica. Ao usar o termo "calamidade financeira" para se referir ao reconhecimento da calamidade pública para fins de incidência dos artigos 65 e 66 da LRF, o Estado dá sequência a uma prática que logo se difundiu na Federação: o delineamento, nos meandros da LRF, de um verdadeiro sistema excepcional de calamidade financeira. O uso do termo, aliás, aponta mesmo para uma ressignificação do instituto legal, ampliando-o como mecanismo próprio do Direito Financeiro.

Depois de Rio de Janeiro e Rio Grande do Sul, foi a vez de o Estado de Minas Gerais reconhecer a calamidade pública para os fins da Lei Complementar $\mathrm{n}^{\circ} 101 / 2000$. Por meio do Decreto $n^{\circ} 47.101 / 2016$, de 05/12/2016, o governo estadual decretou "situação de calamidade financeira", seguindo a tendência inaugurada pelo Executivo gaúcho. As motivações não destoaram das apresentadas pelos outros dois Estados. Foram elencados, no artigo $1^{\circ}$, o "crescente déficit financeiro" e o "histórico crescimento de despesas" como causas aptas a configurar a excepcionalidade.

Seguindo o procedimento determinado pelo artigo 65 da LRF, a Assembleia Legislativa mineira apreciou o tema e aprovou o reconhecimento da calamidade. Diferentemente do procedimento adotado pelo Parlamento fluminense, em que a aprovação se deu por meio de lei, nas Minas Gerais o instrumento invocado foi o da resolução. O Legislativo estadual corroborou a medida governamental pela Resolução $n^{\circ}$ 5.513/2016.

O quarto Estado brasileiro a reconhecer o estado de calamidade para fins da LRF foi Roraima. A medida se deu pela via do Decreto $n^{\circ}$ 26.404-E/2018, de 28/12/2018, que instituiu o "estado de Calamidade Pública Financeira", conforme seu artigo $1^{\circ}$. Vale registrar que, à época, o Estado de Roraima estava sob intervenção federal (G1, 2019b), decretada pelo governo federal em razão de problemas na área de segurança pública e no sistema penitenciário (CONJUR, 2018).

Repetiu-se, de todo modo, no que se refere ao conteúdo significativo da calamidade, o padrão até aqui verificado. Decreto do interventor federal reconheceu o estado de calamidade com justificativas voltadas apenas à situação econômico-financeira. Salientou-se o desequilíbrio das contas públicas, a queda na receita corrente líquida, a composição das despesas e a necessidade de manutenção dos serviços públicos essenciais. Tudo isso está sintetizado na justificativa "grave crise econômica que assola o Estado do Roraima”.

O Decreto $n^{\circ}$ 26.404-E/2018 tem, em seu texto inicial, oito considerações (justificativas) sobre a motivação da sua edição. Uma delas tem, possivelmente, o condão de ir ao encontro da 
delimitação conceitual original do termo "calamidade pública" na LRF: "a crescente migração venezuelana"".

Por essa razão, aliás, há uma peculiaridade no caso de Roraima. A crise migratória pode, sem maiores esforços, ser enquadrada como hipótese típica de calamidade, pelo menos quando se leva em consideração a equiparação do conceito a outros institutos como "grave comoção interna" ou "força maior" 10 .

No entanto, apesar da relevância da crise migratória, a motivação do decreto confere peso maior à crise econômico-financeira do Estado. O fator central que desencadeou a decretação da calamidade, pelo que se extrai do Decreto $n^{\circ}$ 26.404-E/201, parece ter sido de ordem econômico-financeira, e não a situação humanitária registrada à época. Das oito justificativas elencadas pelo instrumento oficial, sete são de ordem econômico-financeira e somente uma faz referência à crise migratória.

Assim como no caso do Rio Grande do Sul, no Estado de Roraima não foram encontrados registros de aprovação da decretação de calamidade pelo Parlamento local. Foi encontrado apenas um registro de aprovação da calamidade decretada em 2020, já sob a pandemia da COVID-19. Trata-se do Decreto Legislativo Estadual $n^{\circ} 01 / 2020$, que, por se referir à situação derivada da pandemia, não está sob o escopo da pesquisa que fundamenta o presente artigo. Ainda assim, é interessante observar que foi o decreto legislativo o instrumento invocado pela Assembleia Legislativa de Roraima para formalizar o estado de calamidade financeira.

No início de 2019, em um movimento que parece ter decorrido da renovação de mandatos gerada pelas eleições de 2018, três Estados brasileiros reconheceram, em janeiro de 2019, a calamidade pública à qual se refere a LRF. O primeiro deles foi o Rio Grande do Norte, que o fez nos primeiros dias de mandato. Por meio do Decreto $n^{\circ} 28.689 / 2019$, de 02/01/2019, o governo estadual decretou o "estado de calamidade financeira", terminologia empregada no artigo $1^{\circ}$ do instrumento normativo.

Entre as justificativas expressas no decreto, repete-se o padrão observado nos outros Estados: trata-se de razões eminentemente econômico-financeiras. São citadas as despesas com pagamento de servidores públicos, a necessidade de manutenção dos serviços públicos e a

\footnotetext{
${ }^{9}$ O Estado de Roraima se deparava, desde 2015, com um intenso fluxo migratório de venezuelanos, em razão da crise política e social por que passa o país vizinho. Entre 2015 e 2019, o Brasil recebeu pelo menos 180 mil solicitações de refúgio por conta deste fenômeno, tendo boa parte desses migrantes se instalado no território roraimense (UNICEF, 2019). Esse foi, então, como esperado, um dos motivos listados à época da edição do decreto que reconheceu o estado de "Calamidade Pública Financeira".

${ }^{10}$ Termo usado pela ministra Rosa Weber no julgamento da Tutela Provisória na Ação Cível Originária no 3.271/MT, em trecho já transcrito neste trabalho (BRASIL, 2019b).
} 
necessidade de enfrentamento do colapso fiscal. Todas essas razões estão sintetizadas na primeira motivação descrita no decreto: "a grave crise econômica, financeira e fiscal que está atingindo fortemente a capacidade de financiamento do setor público".

O Parlamento local, por intermédio de decreto parlamentar (ALRN, 2019), apreciou e aprovou a matéria, conforme determina o artigo 65 da Lei Complementar no 101/2000.

Na sequência, em 17/01/2019, o Estado do Mato Grosso fez movimento similar. Por meio do Decreto no 07/2019, a Administração estadual reconheceu a "situação de calamidade financeira". Os motivos elencados e expressos no instrumento normativo caminham na mesma direção dos invocados pelos outros Estados: aprofundamento do endividamento, deterioração da situação fiscal, alto grau de inadimplência, crescente déficit etc. Dentre os casos analisados nesta pesquisa, o decreto mato-grossense foi o que adotou maior fundamentação, invocando para tanto uma série de motivações, embora a maioria delas tenha estreita ligação com fatores econômico-financeiros.

Seguindo o trâmite legal, o Parlamento estadual aprovou a medida tomada pelo Executivo, pela via da Resolução no 6.237/2019. Corrobora-se, como se vê, observação no sentido da existência de dispersão entre as câmaras legislativas estaduais quanto ao instrumento mais adequado para referendar o reconhecimento da calamidade levado a cabo pelo governo local.

Foi, aliás, à decretação da calamidade no Mato Grosso que a ministra Rosa Weber se referiu na decisão que deferiu a tutela de urgência na Ação Cível Originária $n^{\circ}$ 3.271, já referenciada nesta pesquisa. E, como já destacado, na ocasião, a ministra apontou que o sentido do termo "calamidade financeira" não deve abarcar situações de desequilíbrio fiscal como as invocadas pela Administração mato-grossense na decretação do estado excepcional (BRASIL, 2019b).

Finalmente, o último caso anterior à pandemia da COVID-19 de que se tem notícia é o do Estado de Goiás. O Decreto no 9.392/2019, editado pelo governo estadual em 21/01/2019, instituiu a "situação de calamidade financeira", terminologia empregada no artigo $1^{\circ}$ do diploma. O prazo inicial, de 180 dias, foi prorrogado por mais 180 dias, por intermédio de um outro instrumento, o Decreto ${ }^{\circ}$ 9.481/2019, de 22/07/2019.

Em relação à terminologia, é interessante notar que até mesmo a imprensa apontou a inovação trazida pelo emprego da alcunha "situação de calamidade financeira": "A "situação de calamidade’ não tem previsão legal. O governo de Goiás colocou-a no decreto em uma analogia à situação de 'calamidade pública', recurso constante na Lei de Responsabilidade Fiscal” (EBC, 2019). 
Entre as motivações, novamente ocupam a primazia os fatores estritamente econômicofinanceiros: o elevado e crescente déficit nas contas públicas, a desaceleração do crescimento das receitas, a insuficiência do corte de gastos e a necessidade de manutenção dos serviços públicos essenciais. Como se nota, todos estão atrelados a fatores não decorrentes de uma calamidade na delimitação conceitual do termo que se demonstrou no tópico anterior deste trabalho (causas equiparáveis a estado de defesa, de sítio, guerra ou comoção interna).

Em relação à aprovação da medida pelo Parlamento estadual, houve em Goiás o cumprimento do procedimento previsto na LRF. O Diário Oficial da Assembleia Legislativa de Goiás $n^{\circ} 13.020$, de 24/01/2019, apresenta, na transcrição do debate feito na sessão, a forma pela qual se deu a aprovação. A discussão deu origem ao Decreto Legislativo no 483/2019, de 24/01/2019, que referendou a providência tomada pelo governo estadual.

Abaixo, tabela informativa compila as informações sobre as decretações de calamidade financeira nos Estados brasileiros referidas anteriormente.

Tabela 1 - Decretação da calamidade financeira nos Estados

\begin{tabular}{|c|c|c|c|c|}
\hline Estado brasileiro & $\begin{array}{l}\text { Data da instituição } \\
\text { da calamidade }\end{array}$ & $\begin{array}{c}\text { Norma } \\
\text { instituidora }\end{array}$ & Terminologia & $\begin{array}{l}\text { Instrumento } \\
\text { legislativo de } \\
\text { aprovação }\end{array}$ \\
\hline Rio de Janeiro & $17 / 06 / 2016$ & $\begin{array}{c}\text { Decreto } n^{\circ} \\
45.692 / 2016\end{array}$ & $\begin{array}{l}\text { Estado de calamidade } \\
\text { pública }\end{array}$ & Lei \\
\hline $\begin{array}{l}\text { Rio Grande do } \\
\text { Sul }\end{array}$ & $21 / 11 / 2016$ & $\begin{array}{c}\text { Decreto } n^{\circ} \\
53.303 / 2016\end{array}$ & Calamidade financeira & - \\
\hline Minas Gerais & $05 / 12 / 2016$ & $\begin{array}{l}\text { Decreto } n^{\circ} \\
47.101 / 2016\end{array}$ & $\begin{array}{c}\text { Situação de calamidade } \\
\text { financeira }\end{array}$ & Resolução \\
\hline Roraima & $28 / 12 / 2018$ & $\begin{array}{c}\text { Decreto }^{\circ} \\
26.404-E / 2018\end{array}$ & $\begin{array}{l}\text { Estado de calamidade } \\
\text { pública financeira }\end{array}$ & - \\
\hline $\begin{array}{l}\text { Rio Grande do } \\
\text { Norte }\end{array}$ & 02/01/2019 & $\begin{array}{c}\text { Decreto } n^{\circ} \\
28.689 / 2019\end{array}$ & $\begin{array}{l}\text { Estado de calamidade } \\
\text { financeira }\end{array}$ & $\begin{array}{c}\text { Decreto } \\
\text { parlamentar }\end{array}$ \\
\hline Mato Grosso & $17 / 01 / 2019$ & $\begin{array}{c}\text { Decreto n }^{\circ} \\
07 / 2019\end{array}$ & $\begin{array}{l}\text { Situação de calamidade } \\
\text { financeira }\end{array}$ & Resolução \\
\hline Goiás & $21 / 01 / 2019$ & $\begin{array}{l}\text { Decreto } \mathrm{n}^{\circ} \\
9.392 / 2019\end{array}$ & $\begin{array}{c}\text { Situação de calamidade } \\
\text { financeira }\end{array}$ & $\begin{array}{l}\text { Decreto } \\
\text { legislativo }\end{array}$ \\
\hline
\end{tabular}

Fonte: Portais dos Poderes Executivo e Legislativo estaduais. Elaboração própria.

Relatos na imprensa, coligidos como indicadores da percepção do que se vai consolidando na esfera pública a respeito da temática, corroboram a transmutação do instituto previsto dos artigos 65 e 66 da LRF. 
Dentre outros exemplos, em relação ao caso goiano, à época do reconhecimento da calamidade, o procurador-geral do Ministério Público de Contas de Goiás entendeu que o decreto de calamidade fora usado como sinalizador de dificuldades financeiras para fins de se invocar o sistema excepcional da LRF (G1, 2019a).

Em Minas Gerais, consta do site da Assembleia Legislativa uma análise sobre a decretação da calamidade ocorrida em 2016, atribuída ao governador estadual, em que os motivos elencados para o estado de excepcionalidade são puramente macroeconômicos: crise internacional e nacional, contração do PIB e queda do mercado de commodities (ALMG, 2016).

No Acre, conquanto não se tenha decretado a calamidade, o governo estadual cogitou implantar a medida. Ao ouvir um economista sobre essa situação, o jornal A Gazeta do Acre apresentou uma concepção da medida enquanto forma de se "assumir publicamente que as contas públicas chegaram ao limite". O veículo sinalizou, ainda, que o objetivo da decretação seria conseguir flexibilização orçamentária para descumprir alguns limites da LRF (A GAZETA DO ACRE.COM, 2019).

Todo esse conjunto de evidências está a apoiar a pressuposição aqui assumida de que, anos após a edição da LRF, o sentido atribuído aos dispositivos previstos nos seus artigos 65 e 66 ganhou renovados contornos. Além disso, na visão de alguns setores da sociedade, deixou de se limitar à compreensão do Supremo Tribunal Federal e dos próprios legisladores para dar ensejo aos passos iniciais de institucionalização de um verdadeiro sistema de socorro aos entes federados que enfrentam crises fiscais.

Tem-se em curso, efetivo processo de mudança institucional ${ }^{11}$. Essa caracterização está associada ao fato de que foram transformados, no setor das finanças públicas, os mecanismos de regulação, embora não se tenha tratado de ruptura radical. Ademais, as causas desse processo são endógenas, ou seja, não foram mobilizadas por fatores externos. Como resultado, atrai-se a categoria de mudança institucional (MAHONEY e THELEN, 2010; GOMIDE, 2014).

Em consequência, indaga-se: a LRF como existe hoje comporta essa mudança institucional? Existe de fato respaldo para a nova interpretação atribuída ao sistema de calamidade financeira?

Sustenta-se, aqui, com base na pesquisa que embasou o artigo, que na redação original da Lei Complementar $n^{\circ} 101 / 2000$, considerando os motivos que deram origem à lei, a jurisprudência do Supremo Tribunal Federal, o debate legislativo e a interpretação teleológica

\footnotetext{
${ }^{11}$ Entendendo-se, aí, em linha com o marco da Análise Integral do Direito (CORVAL, 2017), as instituições sob o ponto de vista "regulativo": como instrumentos de normatização da vida, tanto formal (leis, normas positivadas) quanto informalmente (tradições e costumes) (GOMIDE, 2014).
} 
da norma, a resposta seria negativa. Conforme exposto nas seções 1 e 2 , a regulação legislativa restringiu-se a um mecanismo rígido de controle das contas públicas, de modo que a suspensão dessas regras seria possível apenas em hipóteses de situações excepcionais imprevisíveis e de contornos gravosos.

Trata-se, no recorte histórico, de uma consequência do próprio momento social, político e econômico no país quando da elaboração da LRF. Buscava a estabilização da dívida pública, o controle efetivo e duradouro da inflação e a redução do déficit primário, consolidando os debates da década de 1990 em torno do Plano Real (CONTI, 2010, p. 39).

As práticas nos Estados, contudo, que no mais das vezes consubstanciam o espírito dos arranjos e desenhos institucionais, vêm transmutando o sistema de exceção previsto na LRF.

O legislador federal, a reboque, faz seus primeiros esforços na direção de uma renovada configuração das previsões originais da responsabilidade fiscal. Concentrando-se, aqui, unicamente no que tange à LRF - pois há mutações em curso por meio de outros diplomas legislativos, decisões judiciais e emendas constitucionais - a Lei Complementar $n^{\circ}$ 173/2020, editada após a pandemia da COVID-19, trouxe novos desafios ao panorama do Direito Financeiro.

Pode ser que a introdução da nova regulamentação ao ordenamento jurídico brasileiro signifique uma tolerância maior à interpretação levada a cabo pelos Estados brasileiros em crise ou, como nos parece, um sinal de que logo, logo a regulagem da matéria deverá ser reordenada.

\section{Terceiro momento: as novas diretrizes do sistema com a $\operatorname{LC} \mathbf{n}^{0}$ 173/2020}

Com a Lei Complementar $n^{\circ}$ 173/2020, embora intocado o artigo 66 da LRF, o artigo 65 foi bastante modificado em seu conteúdo ${ }^{12}$.

A primeira foi, na verdade, uma supressão. Salta aos olhos a supressão do que dispunha o parágrafo único da redação original, que previa se aplicar "o disposto no caput [do artigo 65] no caso de estado de defesa ou de sítio, decretado na forma da Constituição”.

Na nova redação, não há, no artigo 65, qualquer dispositivo equivalente. Isso pode ter uma repercussão indireta no sistema da calamidade financeira que aqui se analisa. Pode ser que, com essa alteração, o legislador tenha optado por evitar a equiparação do conceito de calamidade pública à ideia original, também já explicitada neste estudo. Se, por um lado, a

\footnotetext{
${ }^{12}$ Art. 65. Na ocorrência de calamidade pública reconhecida pelo Congresso Nacional, no caso da União, ou pelas Assembléias Legislativas, na hipótese dos Estados e Municípios, enquanto perdurar a situação: I - serão suspensas a contagem dos prazos e as disposições estabelecidas nos arts. 23 , 31 e 70; II - serão dispensados o atingimento dos resultados fiscais e a limitação de empenho prevista no art. $9^{\circ}$.
} 
jurisprudência do Supremo Tribunal Federal e o debate legislativo apontavam para uma possível comparação da ideia de calamidade pública com outros estados de excepcionalidade (defesa, sítio, guerra e comoção interna), agora, talvez, essa equiparação hermenêutica seja menos consistente.

Antes, como aqui se defende, não se revelava razoável interpretar o conceito de calamidade pública como um acontecimento de gravidade menor que as dos outros institutos a ela equiparados pela lei. Isso equivaleria a dizer que o sistema excepcional trazido pela LRF em sua redação original não se aplicava às hipóteses de crises econômicas de certo modo esperadas ante os ciclos de altos e baixos históricos do capitalismo, tanto na União quanto nos Estados e Municípios, mas tão somente a fortes abalos ao sistema, equiparados a guerras, comoção interna, estado de defesa e de sítio.

Agora, porém, chancelando-se os movimentos da realidade prática, tem-se um movimento contrário, que, não obstante, não se concretizou plenamente na alteração trazida pela LC n ${ }^{\circ}$ 173/2020, mas que, talvez, nela comece a melhor se delinear. A hipótese é a de que, com a nova redação, o legislador esteja sinalizando que é plausível a inclusão das crises econômicas estaduais e municipais no rol de fatos aptos a ensejar o sistema excepcional de calamidade financeira, possivelmente transpondo para a via legislativa o movimento que na prática já vinha se observando.

Não há menção expressa ao assunto no parecer proferido pelo relator do Projeto de Lei Complementar $n^{\circ}$ 39/2020 (que deu origem à LC n 173/2020) na Câmara dos Deputados. Tampouco há disposição que torne impertinente essa interpretação. Pelo contrário, o relator chegou a externalizar, em seu parecer, que um dos objetivos expressos do projeto é o de reformar o sistema de calamidade pública ${ }^{13}$. Assim, parece-nos plausível a hipótese de que a nova redação tenha o objetivo de suavizar o conceito de calamidade, não mais equiparando-a a situações extremas como o estado de defesa e o estado de sítio.

As próximas alterações de relevo vieram sistematizadas no $\S 1^{\mathrm{o} 14}$. A primeira novidade está associada ao reconhecimento da calamidade. Na redação original, a LRF não especificava

13 “O projeto em apreço aprovado no Senado Federal alcança os seguintes objetivos:

[...] d) alterar a Lei de Responsabilidade Fiscal no que tange a nulidade dos atos que aumentam as despesas com pessoal, e no que diz respeito aos procedimentos e vedações quando da ocorrência de calamidade pública reconhecida pelo Congresso Nacional." (BRASIL, 2020a).

$14 \S 1^{\circ} \mathrm{Na}$ ocorrência de calamidade pública reconhecida pelo Congresso Nacional, nos termos de decreto legislativo, em parte ou na integralidade do território nacional e enquanto perdurar a situação, além do previsto nos inciso I e II do caput: I - serão dispensados os limites, condições e demais restrições aplicáveis à União, aos Estados, ao Distrito Federal e aos Municípios, bem como sua verificação, para: a) contratação e aditamento de operações de crédito; b) concessão de garantias; c) contratação entre entes da Federação; e d) recebimento de transferências voluntárias; II - serão dispensados os limites e afastadas as vedações e sanções previstas e decorrentes dos arts. 35, 37 e 42, bem como será dispensado o cumprimento do disposto no parágrafo único do 
o meio pelo qual o Congresso Nacional ou as Assembleias Legislativas deveriam institucionalizar a excepcionalidade. A LC n 173/2020 supriu essa lacuna ao prever o decreto legislativo como o instrumento adequado para esse propósito.

Outra mudança deixada em aberto foi bem captada pela Confederação Nacional de Municípios (CNM). De acordo com Nota Técnica CNM 36/2020, a nova redação da LRF possibilita que o decreto legislativo do Congresso Nacional que instituir a calamidade pública produza efeitos também sobre Estados e Municípios (BRASIL, 2020b). A Confederação sustenta essa posição afirmando que a extensão aos demais entes federados se restringe à matéria da LRF, razão pela qual poderá ser necessário, para outros fins, o reconhecimento da calamidade na esfera local. A interpretação, de fato, afigura-nos mais adequada, desde que aplicável somente ao inciso I, já que os demais incisos não fazem referência expressa a Estados e Municípios.

A nota da CNM, porém, não opina sobre as situações em que o Congresso Nacional não decretar a calamidade. Nestes casos, Estados e Municípios poderão fazê-lo? Não poderão editar decretos sobre temas que extrapolem os lindes da LRF, mas como, então, proceder caso a União se omita sobre os assuntos da LRF?

Em nossa interpretação, Estados e Municípios terão liberdade para decretar a calamidade, caso o Congresso Nacional não o faça, por duas razões. A primeira delas está relacionada ao princípio da autonomia federativa, que postula deterem os entes federativos autonomia não só administrativa como também política. Não há a autoridade só para executar leis, mas, igualmente, para elaborá-las (MENDES, 2008, p. 798).

Fortalece o raciocínio, ademais, haver a Constituição de 1988 estabelecido a disciplina jurídica das finanças públicas no campo da competência concorrente (CRFB, artigo 24, I). A segunda razão está relacionada à leitura teleológica do dispositivo introduzido na LRF. Aparentemente, a intenção do legislador ao estender os efeitos do decreto legislativo do Congresso Nacional aos Estados e Municípios é ampliar a proteção aos gestores públicos e não subordiná-los ao arbítrio do Parlamento federal. Conforme o professor José Maurício Conti, um dos objetivos da LC n ${ }^{\circ}$ 173/2020 é "dar um alívio financeiro aos entes subnacionais" (CONTI, 2020).

art. $8^{\circ}$ desta Lei Complementar, desde que os recursos arrecadados sejam destinados ao combate à calamidade pública; III - serão afastadas as condições e as vedações previstas nos arts. 14, 16 e 17 desta Lei Complementar, desde que o incentivo ou benefício e a criação ou o aumento da despesa sejam destinados ao combate à calamidade pública. 
A introdução do inciso I do $\$ 1^{\circ}$ parece ter o objetivo de ampliar as flexibilizações da legislação financeira decorrentes da calamidade. Se, antes da modificação, a exceção se limitava aos dispositivos expressamente indicados pelo artigo 65, agora é possível compreender uma vasta gama de normas do Direito Administrativo no escopo de aplicação do sistema de calamidade financeira que se delineia.

O primeiro sinal nessa direção é a forma pela qual o legislador indicou as normas que serão suspensas durante a calamidade. Em vez de se referir a dispositivos específicos, como na redação original, a LRF passou a indicar as normas que serão flexibilizadas pelo tipo de seu conteúdo (aquelas que regulamentam contratação e aditamento de operações de crédito; concessão de garantias; contratação entre entes da Federação e recebimento de transferências voluntárias).

Isso tem um efeito prático imediato: a quantidade de normas suspensas durante a calamidade será maior. Deve-se levar em conta que as escolhas lexicais do legislador comportam vasta margem de conformação. Somente em relação à contratação de operações de crédito e concessão de garantia, por exemplo, não são poucas as normas jurídicas que versam sobre o tema, direta ou indiretamente, principal ou secundariamente. A nível constitucional são pelo menos 8 dispositivos, além de 6 leis complementares (sendo uma delas a LRF), 22 leis ordinárias, decretos ou medidas provisórias, 8 resoluções do Senado Federal, 4 resoluções do Conselho Monetário Nacional, 8 portarias do Ministério da Economia, 5 portarias da Secretaria do Tesouro Nacional, 26 pareceres da Procuradoria Geral da Fazenda Nacional e da AdvocaciaGeral da União e 11 notas técnicas, manuais e demais normas técnicas da Secretaria do Tesouro Nacional (BRASIL, 2019b).

O segundo sinal de alargamentos das exceções à LRF colhe-se dos termos usados para indicar o novo objeto da flexibilização da responsabilidade fiscal. $\mathrm{O}$ inciso I indica que serão dispensados "limites, condições e demais restrições [...], bem como sua verificação". Ou seja, além de não haver uma restrição quanto às normas que serão suspensas, também não se delimita o tipo de dispositivo que será suspenso. A conclusão que nos parece mais razoável é a de que será dispensada a aplicação de todos os dispositivos que tenham alguma familiaridade com a ideia de limite, condição ou restrição de qualquer natureza.

Resta reforçada, aí, aliás, a conclusão a que se chegou anteriormente: a quantidade de normas suspensas durante a calamidade pública passa a ser muito maior do que era antes da edição da LC $^{\circ}{ }^{\text {1 }}$ 173/2020. A Nota Técnica 36/2020 da CNM explicita entendimento similar (BRASIL, 2020b). 
Sigamos em frente e vejamos, em bloco, os incisos II e III do $\S 1^{\circ}$. Se por um lado o inciso I adotou uma terminologia genérica, que possibilita uma ampliação da margem de aplicação do sistema de calamidade financeira, aqui ocorre o oposto. O inciso II delimita expressamente os dispositivos que serão flexibilizados (todos da própria LRF).

Aqui, porém, a função da delimitação mais precisa não parece ser outra que não a de somente ampliar ou restringir a margem de aplicação do sistema de calamidade financeira, pois este papel coube ao inciso I. O objetivo dos incisos II e III seria proteger com mais rigor e segurança o administrador público das sanções decorrentes da violação aos artigos $8^{\circ}$, parágrafo único, 35, 37 e 42, favorecendo, assim, o empreendimento vigoroso de esforços para sanar as consequências da calamidade. Esse talvez seja o motivo que justifique a escolha por uma terminologia mais objetiva especificamente nos incisos II e III, que se contradiz com a redação alargada empregada no inciso I.

Em relação à extensão do inciso III, a propósito, já se ensaiam divergências na ainda rarefeita literatura sobre o tema. Enquanto a CNM aponta para um sentido mais restrito, a Secretaria do Tesouro Nacional amplia a aplicação do dispositivo. A Nota Técnica 36/2020 da CNM limita o uso de receitas vinculadas às receitas excedentes de anos anteriores, enquanto a Nota Técnica SEI n 21231/2020/ME, da Secretaria do Tesouro Nacional, entende ser possível também o uso de receitas vinculadas do orçamento corrente (MALUF, 2020).

Em nossa interpretação, a limitação apontada pela CNM não deve prevalecer, visto que, apesar de configurar entendimento alinhado ao postulado geral da responsabilidade fiscal, não encontra respaldo na LRF. Não se deve presumir que o legislador tenha optado por restringir de forma tão acintosa a previsão do III, já que não há qualquer fundamento textual ou nas práticas anteriores para essa conclusão. Assim, embora se possa até cogitar de uma possível atuação mais responsável por meio da limitação proposta pela CNM ao texto, a orientação legislativa caminha em sentido abrangente, capaz de ampliar os meios instrumentais de ação, ao permitir também o uso das receitas vinculadas do orçamento corrente.

Talvez fosse uma alternativa entre os Poderes, em termos de construção prática, esperar que a excepcionalidade fosse regulamentada para as situações concretas, por meio de lei que ajuste, à situação de crise, a Lei de Diretrizes Orçamentárias (LDO). A LDO, com eficácia disciplinadora da política fiscal para o exercício (CRFB, artigo 165, §2º LRF, artigo $4^{\circ}$ ), configura espaço favorável à harmonização dessa ordem. 
Enfrentadas as alterações introduzidas pelo $\S 1^{\circ}$, passa-se à análise do $\S 2^{\circ 15}$. Como se nota, o objetivo do $\S 2^{\circ}$ parece ser o de delimitar a incidência do regime financeiro excepcional, estabelecendo, para isso, restrição territorial-temporal (inciso I, alínea a) e, também, limitação material (inciso I, alínea b). Partindo dessa hipótese, razoável seria a percepção de que os enunciados trazem uma possível redenção do movimento de alargamento feito nos anteriores. No $\S 2^{\circ}$, assim, ter-se-ia querido restringir um pouco mais a incidência do sistema de calamidade financeira, em razão da grande ampliação que se viu no $\S 1^{\circ}$. Sinal disso seria a expressa referência ao parágrafo anterior: "O disposto no $\S 1^{\circ}$ deste artigo [...]".

Nada obstante, é necessário considerar que esse esforço de calibragem tem alcance reduzido. A abertura normativa trazida ao texto da LRF alcança aspectos nucleares do sistema, enquanto o que se vê nos presentes dispositivos é apenas uma complementação, um movimento de conformação e ajustamento. O cerne do sistema de calamidade financeira permanece inalterado: seu objeto, seus pressupostos e seus objetivos. O acréscimo foi tão somente o estabelecimento de algumas fronteiras circunstanciais (ou seja, não elementares) de aplicação do regime excepcional.

Em relação ao inciso II, chama a atenção a sua brevidade. Enquanto os dispositivos que construíram o objeto do sistema foram amplos em suas previsões, este outro, que prevê a manutenção dos mecanismos de controle e transparência, não se dedicou a um grande detalhamento.

Não é desarrazoado supor que, durante uma calamidade pública, a fiscalização não poderá ser desempenhada da mesma maneira que no sistema ordinário, tendo em vista as excepcionalidades que a calamidade poderá trazer, a depender de suas características. A pandemia decorrente da COVID-19, por exemplo, que serviu de catalisador para a edição da LC n ${ }^{\circ}$ 173/2020, impôs uma série de restrições a mecanismos ordinários de transparência. Um exemplo se vê nas audiências públicas ${ }^{16}$, que precisaram ser adaptadas durante o estado pandêmico. A Nota Técnica 36/2020 da CNM sugere a realização dessas audiências, tão essenciais à democratização do processo orçamentário e fiscal, por meios virtuais (BRASIL, 2020b). A Secretaria do Tesouro Nacional, aliás, recomendou a manutenção das audiências

\footnotetext{
${ }^{15} \S 2^{\circ} \mathrm{O}$ disposto no $\S 1^{\circ}$ deste artigo, observados os termos estabelecidos no decreto legislativo que reconhecer o estado de calamidade pública: I - aplicar-se-á exclusivamente: a) às unidades da Federação atingidas e localizadas no território em que for reconhecido o estado de calamidade pública pelo Congresso Nacional e enquanto perdurar o referido estado de calamidade; b) aos atos de gestão orçamentária e financeira necessários ao atendimento de despesas relacionadas ao cumprimento do decreto legislativo; II - não afasta as disposições relativas a transparência, controle e fiscalização.

${ }^{16}$ As audiências públicas estão previstas na LRF como um dos mecanismos de transparência na gestão fiscal, conforme artigo $48, \S 1^{\circ}$, I, da Lei Complementar ${ }^{\circ} 101 / 2000$.
} 
quadrimestrais de acompanhamento da LDO (Lei de Diretrizes Orçamentárias), adaptadas para meio virtual, desde que com ampla divulgação e com mecanismos de interação (BRASIL, 2020c).

Portanto, se a fiscalização poderá ser comprometida, a disposição do inciso II talvez se torne insuficiente para salvaguardar a accountability democrática, já que não prevê qualquer procedimento apto a dar mais efetividade à transparência e ao controle durante o regime excepcional. Um bom exemplo de medida capaz de aprimorar o controle durante a excepcionalidade foi dado pela Emenda Constitucional n ${ }^{\circ}$ 106/2020, popularmente conhecida como "Orçamento de Guerra", em seu artigo 9017. A Emenda, diferentemente do sistema de calamidade financeira da LRF, tem aplicação restrita às emergências de saúde pública decorrentes de pandemia, conforme seu artigo $1^{\mathrm{o}}{ }^{18}$, diferentemente do amplo escopo de “calamidade pública” definido pela LRF. O Ministério da Economia, ademais, vem buscando aprimorar as ferramentas para sanar essa fragilidade decorrente da omissão regulatória da LRF. Detalha, assim, na Nota Técnica SEI n 21231/2020/ME, instrumentos de transparência e controle que deverão ser mantidos ou implementados durante a calamidade (BRASIL, 2020c).

Finalmente, veja-se o que dispõe o $\S 3^{\circ}$ do artigo 65 da LRF, também introduzido pela LC $\mathrm{n}^{\mathrm{o}} 173 / 2020^{19}$. Nos termos do artigo 29, IV, da LRF, concessão de garantia é o "compromisso de adimplência de obrigação financeira ou contratual assumida por ente da Federação ou entidade a ele vinculada".

A previsão do $\S 3^{\circ}$ do artigo 65 parece ter por objetivo complementar o que dispõe o artigo 40 da mesma lei, que disciplina a prestação de garantia e contragarantia pelos entes públicos em operações de crédito, atribuindo certo rigor a esse tipo de operação, conforme os princípios de estabilidade que nortearam a edição da LRF, como já demonstrado no item 1 deste artigo.

Coube à LC $n^{\circ}$ 173/2020, então, suspender a eficácia do procedimento ordinário de aditamento das operações de crédito, garantindo-lhe maiores condições de celeridade para a

\footnotetext{
${ }^{17}$ Art. $9^{\circ}$ Em caso de irregularidade ou de descumprimento dos limites desta Emenda Constitucional, o Congresso Nacional poderá sustar, por decreto legislativo, qualquer decisão de órgão ou entidade do Poder Executivo relacionada às medidas autorizadas por esta Emenda Constitucional.

${ }^{18}$ Art. $1^{\circ}$ Durante a vigência de estado de calamidade pública nacional reconhecido pelo Congresso Nacional em razão de emergência de saúde pública de importância internacional decorrente de pandemia, a União adotará regime extraordinário fiscal, financeiro e de contratações para atender às necessidades dele decorrentes, somente naquilo em que a urgência for incompatível com o regime regular, nos termos definidos nesta Emenda Constitucional.

${ }^{19} \S 3^{\circ}$ No caso de aditamento de operações de crédito garantidas pela União com amparo no disposto no $\S 1^{\circ}$ deste artigo, a garantia será mantida, não sendo necessária a alteração dos contratos de garantia e de contragarantia vigentes.
} 
obtenção de recursos financeiros. Nessa perspectiva, o objetivo do dispositivo parece ser o de facilitar a contenção dos danos decorrentes da calamidade.

Na perspectiva de Humberto Ávila (ÁVILA, 2012), pode-se entender as alterações empreendidas na Lei de Responsabilidade Fiscal como um movimento de reconfiguração de regras fiscais que buscam dar eficácia normativa ao princípio da responsabilidade fiscal, inegável manifestação da accountability nas democracias contemporâneas. A responsabilidade fiscal figuraria não apenas como sedimentação de uma crença econômica de ancoragem da confiança do livre mercado e da prioridade dos mecanismos monetários de condução da economia, mas, com as alterações trazidas, como um efetivo eixo norteador da administração pública no Brasil.

Em certo sentido, as mudanças no sistema de calamidade financeira estariam a dar razão a todas as advertências que, desde o surgimento da LRF, eram levantadas contra as pretensões de trava, por inspirações de austeridade fiscal, do recurso aos instrumentos de finanças públicas para orientar o processo econômico (CARVALHO, 2020, capítulo 2).

Ainda que não escancarada, a porta que bloqueia, muitas vezes, a livre passagem e intercâmbio das ideias e interesses, estaria, agora, entreaberta, forçando pelas frestas acomodações que realisticamente mantenham sustentação e equilíbrio orçamentários, financeiros e econômicos. Nenhuma acomodação, porém, deve se restringir à garantia do mercado. Em contraposição, deve-se ter no horizonte a manutenção da sociabilidade e da convivência política democrática no enfrentamento dos problemas institucionais que sempre esbarram nas finanças públicas.

\section{Conclusão}

Diante da análise empreendida neste estudo, parece razoável concluir que, entre os anos 2000 e 2020, houve um processo de ressignificação do sistema de calamidade financeira previsto na Lei de Responsabilidade Fiscal, a começar pela própria alcunha "sistema de calamidade financeira". Como demonstrado nas páginas anteriores, a construção deste mecanismo excepcional se deu a partir de necessidades práticas dos Estados federados, que operaram um processo hermenêutico de remodelação dos objetivos da norma jurídica.

Parece claro que a jurisprudência do Supremo Tribunal Federal, a literatura jurídica especializada e os próprios debates parlamentares que deram origem à Lei Complementar $\mathrm{n}^{\circ}$ 101/2000 caminhavam num sentido comum: a eficácia do princípio responsabilidade fiscal. Na ideia de princípio e regra jurídicos delineada por Humberto Ávila (ÁVILA, 2012), o 
ordenamento jurídico, desde o início do século XXI, vinha prezando pela implantação de regras mais rígidas para a satisfação do referido princípio.

No entanto, o que se viu nos anos seguintes, especialmente após a virada econômica causada pela crise de 2015 (CARVALHO, 2018), foi um pedido de socorro em massa. Vários Estados brasileiros (Rio de Janeiro, Rio Grande do Sul, Rio Grande do Norte, Roraima, Goiás, Minas Gerais e Mato Grosso, pelo menos) repetiram um movimento iniciado no Rio de Janeiro e disseminado entre os outros: a decretação de calamidade pública com base em fatores estritamente econômicos, não decorrentes de desastres naturais ou abalos equivalentes a estado de defesa, estado de sítio, guerra ou grave comoção interna. Tudo isso antes da pandemia da COVID-19 iniciada em 2020.

A despeito da irregularidade apontada por alguns, entre eles o professor José Maurício Conti (CONTI, 2016), fato é que a edição da Lei Complementar n ${ }^{\circ}$ 173/2020 trouxe novos contornos à controvérsia. Embora após o advento do diploma legal pareça mais plausível a aplicação do sistema de calamidade financeira como sistema de socorro aos Estados fiscalmente abalados, o impasse persiste.

Este impasse tem uma origem profunda, que não é facilmente superável. Trata-se de uma questão federativa e republicana. Há aqui dois níveis de relação política: a relação entre os três poderes, já que o mecanismo previsto pelo Legislativo passa a ser ressignificado pelo Executivo, sob controle do Judiciário; e a relação entre os entes federados, tendo em vista que o socorro concedido aos Estados implica em redimensionamento das contas da União, já que muitas vezes esta é credora daqueles.

A pandemia da COVID-19 tornou inadiável a necessidade de reforma e ampliação do sistema de calamidade financeira em vigor. Isso ficou evidente, por exemplo, na apreciação da Medida Cautelar na Ação Direta de Inconstitucionalidade n ${ }^{\circ} 6.357$ pelo Supremo Tribunal Federal. Nela, a Presidência da República arguiu a interpretação conforme a Constituição de alguns dispositivos da Lei de Responsabilidade Fiscal que impunham uma série de condições ao gasto público, condições essas que não poderiam ser satisfeitas a tempo da implementação de políticas públicas direcionadas ao combate da pandemia. O relator, ministro Alexandre de Moraes, concedeu liminarmente a medida cautelar, para afastar a exigência de demonstração de adequação e compensação orçamentárias em relação à criação/expansão de programas públicos destinados ao enfrentamento da pandemia (BRASIL, 2020d). 


\section{Referências}

ABRAHAM, Marcus. Estado de calamidade financeira e a Lei de Responsabilidade Fiscal. Portal Jota, 2016. Disponível em https://www.jota.info/opiniao-e-analise/colunas/colunafiscal/coluna-fiscal-estado-de-calamidade-financeira-e-lrf-07072016. Acesso em: 31 jul. 2020.

ALVES, Izabela Fernanda Luz. Análise do Princípio Federativo como limitação constitucional ao poder de tributar. Trabalho de Conclusão de Curso, Universidade de Brasília, Brasília, 2011.

ASSEMBLEIA Legislativa de GO aprova decreto de calamidade financeira. Empresa Brasil de Comunicação - EBC. Brasília, 2019. Disponível em:

https://agenciabrasil.ebc.com.br/politica/noticia/2019-01/assembleia-legislativa-de-go-aprovadecreto-de-calamidade-financeira. Acesso em: 31 jul. 2020.

ÁVILA, Humberto. Sistema Constitucional Tributário. 5. ed. São Paulo, Saraiva, 2012.

BARROSO, Luís Roberto. Curso de direito constitucional contemporâneo: os conceitos fundamentais e a construção do novo modelo. 9. ed. São Paulo, Saraiva, 2020.

BRASIL. Câmara dos Deputados. Parecer ao Projeto de Lei Complementar no 39, de 2020. Brasília, 2020. Disponível em https://www.camara.leg.br/proposicoesWeb/prop _mostrarintegra;jsessionid=FB6F40851C0103F0E6E9C1777247277C.proposicoesWebExtern o2? codteor=1890092\&filename=Tramitacao-PLP+39/2020. Acesso em: 31 jul. 2020.

BRASIL. Câmara dos Deputados. Projeto de Lei Complementar no 18/1999. Brasília, 1999. Disponível em https://www.camara.leg.br/proposicoesWeb/fichadetramitacao ?idProposicao=38154. Acesso em: 22 jul. 2020.

BRASIL. Confederação Nacional de Municípios. Nota Técnica no 36/2020. Brasília, 2020. Disponível em https://www.cnm.org.br/cms/biblioteca/NT_36_2020_Orientacoes-aosMunicipios-sobre-o-Programa-Federativo-de-Enfrentamento-ao-Coro navirus_.pdf. Acesso em: 22 jul. 2020.

BRASIL. Secretaria do Tesouro Nacional. Manual para instrução de pleitos. Brasília, 2019. Disponível em https://conteudo.tesouro.gov.br/manuais. Acesso em: 22 jul. 2020.

BRASIL. Secretaria do Tesouro Nacional. Nota Técnica SEI no 21231/2020/ME. Brasília, 2020. Disponível em https://siconfi.tesouro.gov.br/siconfi/pages/public/ conteudo/conteudo .jsf?id=24703. Acesso em: 22 jul. 2020.

BRASIL. Supremo Tribunal Federal. Medida Cautelar em Ação Direta de Inconstitucionalidade no 4.048-1/DF, julgada em 14/05/2008. Relator: Ministro Gilmar Mendes. Pesquisa de jurisprudência, Acórdãos. Disponível em http://redir.stf.jus.br/paginadorpub/paginador.jsp?docTP=AC\&docID=542881. Acesso em: 22 jul. 2020. 
BRASIL. Supremo Tribunal Federal. Medida Cautelar na Ação Direta de Inconstitucionalidade $n^{\circ}$ 6.357/DF, julgada em 29/03/2020. Relator: Ministro Alexandre de Moraes. Pesquisa de jurisprudência. Disponível em http://portal.stf.jus.br /processos/downloadPeca.asp?id=15342780618\&ext=.pdf. Acesso em: 31 jul. 2020.

BRASIL. Supremo Tribunal Federal. Tutela Provisória na Ação Cível Originária nº 3.271/DF, julgada em 24/06/2019. Relatora: Ministra Rosa Weber. Pesquisa de jurisprudência, Acórdãos. Disponível em http://portal.stf.jus.br/ processos/downloadPeca.asp?id=15340474400\&ext=.pdf. Acesso em: 22 jul. 2020.

CALAMIDADE financeira de estados não é reconhecida pelo governo. G1, 2016. Disponível em http://g1.globo.com/bom-dia-brasil/noticia/2016/12/calamidade-financeira-de-estadosnao-e-reconhecida-pelo-governo.html. Acesso em: 31 jul. 2020.

CARVALHO, Laura. Curto-circuito: o vírus e a volta do Estado. São Paulo, Todavia, 2020.

CARVALHO, Laura. Valsa brasileira: do boom ao caos econômico. São Paulo Todavia, 2018.

CONTI, José Maurício. Crise leva as finanças públicas ao "estado de calamidade". Revista Consultor Jurídico, 2016. Disponível em https://www.conjur.com.br/2016-jun-28/contasvista-crise-leva-financas-publicas-estado-calamidade. Acesso em: 31 jul. 2020.

CONTI, José Maurício. Estados e municípios pedem socorro. Portal Jota, 2020. Disponível em https://www.jota.info/paywall?redirect_to=//www.jota.info/opiniao-e-analise/colunas /coluna-fiscal/estados-e-municipios-pedem-socorro-23072020. Acesso em: 24 jul. 2020.

CONTI, José Maurício. Planejamento e Responsabilidade Fiscal. In: CONTI, José Maurício; SCAFF, Fernando Facury. Lei de Responsabilidade Fiscal - 10 anos de vigência - Questões atuais. Florianópolis, Conceito Editorial, 2010.

CORVAL, P. R. S.. Análise Integral do Direito (AID): primeiras aproximações e apontamentos para a pesquisa no direito público. Revista de Informação Legislativa, v. 54, p. 81-111, 2017.

CRISE migratória venezuelana no Brasil. UNICEF, 2019. Disponível em https://www.unicef.org/brazil/crise-migratoria-venezuelana-no-brasil. Acesso em: 31 jul. 2020.

CRUZ, Cláudia Ferreira; AFONTO, Luís Eduardo. Gestão fiscal e pilares da Lei de Responsabilidade Fiscal: evidências em grandes municípios. Revista de Administração Pública, vol. 52, n. 1. Rio de Janeiro, 2018.

DECRETO de intervenção federal em Roraima é publicado no Diário Oficial da União.

Revista Consultor Jurídico - CONJUR, 2018. Disponível em https://www.conjur.com.br/2018-dez-10/decreto-intervencao-federal-roraima-publica do-dou. Acesso em: 31 jul. 2020. 
DEPUTADOS referendam estado de calamidade financeira no RN. Assembleia Legislativa do Rio Grande do Norte - ALRN. Natal, 2019. Disponível em http://www.al.rn.gov.br/portal/noticias/. Acesso em: 31 jul. 2020.

DIAS, Roberto; TEDESCO, Thomaz Fiterman. Covid-19, Direitos Sociais Trabalhistas e Jurisprudência da Crise: o Supremo Tribunal Federal em Postura Pragmática. Revista Direito Público, Brasília, v. 17, n. 96, p. 308,331, nov./dez., 2020. Disponível em: https://www.portaldeperiodicos.idp.edu.br/direitopublico/article/view/4444/Mello\%3B\%2020 20. Acesso em: 03 dez. 2021.

ECONOMISTA explica o significado de calamidade financeira. A Gazeta do Acre.com. Rio Branco, 2019. Disponível em https://agazetadoacre.com/2019/01/ economista-explica-osignificado-de-calamidade-financeira/. Acesso em: 31 jul. 2020.

ESPECIALISTAS explicam decreto de calamidade financeira de Goiás. G1, 2019. Disponível em https://g1.globo.com/go/goias/noticia/2019/01/22/especialistas-explicam-decreto-decalamidade-financeira-de-goias.ghtml. Acesso em: 31 jul. 2020.

GOIÁS. Diário da Assembleia. Número 13.020, de 24/01/2019. Goiânia, 2019. Disponível em https://saba.al.go.leg.br/v1/view/transparencia/public/hRpwcS7nFUmn

V8urNq2Q8Q==/diario-alego-2019-01-24.pdf. Acesso em: 31 jul. 2020.

GOMIDE, Alexandre de Ávila. Tipos e Dinâmicas de Mudança Institucional: As Agências Reguladoras de Transportes no Brasil. Revista de Ciências Sociais, v. 57, n. 3. Rio de Janeiro, 2014.

GUEDES, José Rildo de Medeiros. Comentários à Lei de Responsabilidade Fiscal. IBAM, BNDES. Rio de Janeiro, 2001.

KHAIR, Amir Antônio. Lei de Responsabilidade Fiscal: guia de orientação para as prefeituras. Ministério do Planejamento, Orçamento e Gestão, BNDES. Brasília, 2000.

MAGALHÃES, Andréa. Jurisprudência da crise: uma perspectiva pragmática. Rio de Janeiro: Lumen Juris, 2017.

MAHONEY, James; THELEN, Kathleen. A Theory of Gradual Institutional Change. In: MAHONEY, J.; THELEN, K. (org.). Explaining institutional change: ambiguity, agency, and power. Cambridge, Cambridge University Press, 2010.

MALUF, André Luiz. Novo Regime de Exceção Fiscal da LC 173/2020 surge em boa hora. Revista Consultor Jurídico, 2020. Disponível em https://www.conjur.com.br /2020-jun12/andre-maluf-regime-excecao-fiscal-lc-1732020. Acesso em: 24 jul. 2020.

MENDES, Gilmar Ferreira. Curso de direito constitucional. 7. ed. São Paulo, Saraiva, 2012.

MENDES, Gilmar Ferreira; COELHO, Inocêncio Mártires; BRANCO, Paulo Gustavo Gonet. Curso de direito constitucional. 2. ed. São Paulo, Saraiva, 2008.

MORAES, Guilherme Peña de. Curso de direito constitucional. 12. ed. São Paulo, Atlas, 2020. 
NASCIMENTO, Edson Ronaldo do; DEBUS, Ilvo. Lei Complementar $\mathbf{n}^{\mathbf{0}}$ 101/2000 Entendendo a Lei de Responsabilidade Fiscal. 2. ed. Brasília, ESAF, 2002.

PINHEIRO, Alexandre Sousa. A jurisprudência da crise: Tribunal Constitucional português (2011-2013). Observatório da Jurisdição Constitucional. Brasília, v. 7, n. 1, p. 168/189, jan./jun., 2014. Disponível em:

https://www.portaldeperiodicos.idp.edu.br/observatorio/article/view/961/641. Acesso em: 03 dez. 2021.

PLENÁRIO aprova projeto que reconhece calamidade financeira. Assembleia Legislativa de Minas Gerais - ALMG. Belo Horizonte, 2016. Disponível em https://www.almg.gov.br/acompanhe/noticias/arquivos/2016/12/07_plenario_projeto_calamid ade_financeira.html. Acesso em: 31 jul. 2020.

RIO GRANDE DO SUL. Assembleia Legislativa. Portal da Assembleia Legislativa do Rio Grande do Sul - Pesquisa da Legislação Estadual. Porto Alegre, 2020. Disponível em: http://www.al.rs.gov.br/legislativo/LegislacaoEstadual.aspx. Acesso em: 31 jul. 2020.

RORAIMA decreta estado de calamidade financeira. G1. Boa Vista, 2019. Disponível em https://g1.globo.com/rr/roraima/noticia/2019/01/03/roraima-decreta-estado-de-cala midadefinanceira.ghtml. Acesso em: 31 jul. 2020.

SACRAMENTO, Ana Rita; PINHO, José Antônio Gomes. Transparência na Administração Pública: o que mudou depois da Lei De Responsabilidade Fiscal? Um estudo exploratório em seis municípios da região metropolitana de Salvador. Revista de Contabilidade da UFBA, v.1, n. 1. Salvador, 2007.

SILVA, José Afonso da. Curso de direito constitucional positivo. 25. ed. São Paulo, Malheiros, 2005.

TARTUCE, Flávio. Manual de direito civil: volume único. 7. ed. Rio de Janeiro, Forense, 2017. 